\title{
Entre recalques e hibridismos: marcas pós-coloniais no conto "O efeito estufa", de João Melo
}

\author{
Between repressions and \\ hybridity: postcolonial marks in \\ the tale "The greenhouse effect", \\ by João Melo
}

Francisco das Chagas Souza Costa https://orcid.org/0000-0001-8476-8014

Resumo: Na rota dos estudos pós-coloniais aplicados ao texto literário, o presente artigo objetiva apresentar uma reflexão acerca de alguns resquícios traumáticos e dos hibridismos culturais oriundos do processo de colonização portuguesa em Angola a partir da literatura de João Melo, tendo como corpus específico o conto "O efeito estufa" o qual faz parte da obra "Filhos da Pátria". Centrado no protagonista Charles Dupret, o conto analisado mostra as nuances de um processo de hibridização e de forte recalque presente nos sujeitos que foram submetidos à empreitada dos colonizadores. O caráter psicocultural é marcante nessa narrativa o qual é representado com um tom irônico pelo autor, pois a visão nacionalista-racial do personagem principal é posta como despropositada, tornando-se, portanto, ridícula. Como suporte teórico para esse conjunto de ideias recorre-se a estudiosos como Bhabha (1998), Said (1990,2007), Fanon (2008), entre outros. Tem-se a expectativa de contribuir com as discussões da incipiente forma de abordagem do texto literário denominada de crítica pós-colonial.

Palavras-chave: Angola; Hibridismo; Pós-colonial; Recalque.

Abstract: In the course of the postcolonial studies applied to the literary text, the present article aims to present a reflection about some traumas and cultural hybrids originating from the process of Portuguese colonization in Angola from the literature of João Melo, having as a specific corpus the tale "Greenhouse effect" which is part of the work "Sons of the Motherland". Centered on the protagonist Charles Dupret, the tale analyzed shows the nuances of a process of hybridization and 
strong repression present in the subjects who were submitted to the colonizers. The psycho-cultural character is striking in this narrative which is represented with an ironic tone by the author, for the nationalist-racial vision of the main character is put as unreasonable, thus becoming ridiculous. As a theoretical support for this set of ideas, scholars such as Bhabha (1998), Said (1990,2007), Fanon (2008), and others are used. It is hoped to contribute with the discussions of the incipient form of approach of the literary text denominated of postcolonial criticism.

Keywords: Angola; Hybridism; Postcolonial; Recalque.

\section{Considerações Iniciais}

O modo como o processo de colonização portuguesa, em países africanos, se configurou e os seus reflexos na cultura e na vida social dessas comunidades nativas, são por demais diversos e heterogêneos. Dessa forma, determiná-los, categoricamente, seria uma pretensão utópica. O que se pode, nesse caso, é perceber alguma nuança do vasto e marcante legado dessa relação, por vezes conflituosa, entre metrópole e colônia.

A partir desse ponto, é plausível tentar uma compreensão razoável no tocante à constituição dos sujeitos colonizados que estão em incessante processo de vir a ser, uma vez que a influência externa ocasionou uma quebra de traços culturais e da própria identidade desses povos os quais passam a conviver com uma realidade que é híbrida e, por isso, ligada a toda uma herança colonial. Assim, aspectos como língua, religião, costumes, organização e práticas políticas, atividades econômicas, entre outros, são inseridas em espaços que acabam perdendo sua autonomia e são submetidas a uma nova configuração sociocultural na qual o passado (précolonial) e o presente (pós-colonial) se chocam e podem resultar em recalques ou uma espécie de fuga para não reconhecer as marcas históricas deixadas pela colonização. O entendimento de que não é exequível alcançar uma autenticidade após essa fusão de culturas parece ser o mais razoável, já que o hibridismo, nessa lógica, tornou-se patente e irreversível.

A arte literária, nesse sentido, insere-se como uma manifestação cultural ímpar na capacidade de representação de vários aspectos de uma coletividade que teve alterações consideráveis de seu cotidiano devido a empreitada colonizadora. A própria noção de póscolonialismo, no escopo da literatura, remete a contextos históricos, espaço-temporais e culturais nos quais a identidade de sujeitos é reformulada diante de um mundo cujas fronteiras de nacionalidade acabam sendo rompidas.

O Colonialismo de vertente portuguesa, nessa conjuntura, tem no continente africano um viés distinto do que foi realizado no Brasil. Em terras brasileiras, o indivíduo português é assimilado por um processo de mestiçagem de forma tão densa que a consequência foi a 
construção de uma identidade peculiar capaz de se mostrar como algo novo a ponto de negar, com veemência, aspectos da matriz europeia. Em África há um maior distanciamento entre portugueses e autóctones, ou seja, o colonizador não foi absorvido pela conjuntura de interação com os sujeitos colonizados, o que reduziu o processo de mistura racial se comparado à antiga colônia portuguesa no continente americano.

Sendo assim, a construção de um imaginário de superioridade do branco europeu em relação ao negro africano causa uma imposição cultural que provoca traumas em indivíduos que ao longo do processo histórico tiveram abalos psicológicos no que se refere a um sentimento de inferioridade que foi sendo inserido de modo sistemático. Em outras palavras, pode-se dizer que a dominação de um território pertencente a outros povos e culturas, ocorreu não só através da força física, mas também, com uma inserção de ideologias que acabaram controlando a mente de grande parte dos indivíduos das sociedades subjugadas.

A situação de Angola, nessa conjuntura, é um caso paradigmático, pois o demorado e sofrido processo de independência fez com que os resquícios deixados pelos colonizadores portugueses não fossem digeridos de forma satisfatória. Com isso, uma série de desajustes são pertinentes na constituição da identidade dos sujeitos angolanos. De outro modo, pode-se dizer que o choque causado pelas mudanças de natureza político-cultural implantadas pelo colonizador trouxe à mente desses indivíduos a necessidade de uma redescoberta das suas raízes identitárias.

Um dos roteiros mais frequentes nessa luta por um autorreconhecimento do sujeito póscolonial, é a opção por um nacionalismo extremado coadunado, nesse caso da África, ao elemento racial. Não obstante, os radicalismos que envolvem conceitos de nação e raça, os movimentos em defesa da libertação do colonialismo português têm em seu bojo a ascensão de uma classe intelectual de indivíduos colonizados que passaram a refletir acerca das perdas e ganhos de todo processo de colonização. É lógico que, de forma pragmática, a conquista da independência política dos países luso-africanos, que veio a se concretizar apenas na segunda metade do século XX, envolveu a luta armada e o terror da guerra civil.

Assim, após todo esse doloroso processo de separação, ocorre a tentativa do que se pode chamar de descolonização. A reafirmação de elementos culturais e da própria condição racial parece ser o cerne do pensamento de indivíduos que precisam se reencontrar para definir quem realmente são. Embora já "contaminados" pelo "outro", alguns sujeitos colonizados tentam negar a sua própria formação híbrida.

Tal circunstância parece ficar evidenciada em algumas representações literárias nas quais os personagens (representantes dos sujeitos colonizados) simbolizam essa caricatura de sujeitos 
que se engajam, com veemência, contra todo um arcabouço cultural que se misturou à cultura dos nativos. É possível constatar uma amostra dessas contradições, nas quais recalques e hibridismos se contrabalançam no conto "O efeito estufa" do angolano João Melo. Um estudo cuidadoso do referido conto pode revelar o quanto é necessário superar os traumas de um período conturbado que envolveu inúmeros territórios que até então eram intactos em relação à influência ocidental.

Sendo assim, a análise que se propõe do supracitado conto do escritor de Angola se direciona a um viés no qual se percebe a necessidade da superação de sentimentos de inferioridade que resultam em ideias e ações contraditórias, já que buscam não reconhecer a constituição, inevitavelmente, híbrida daqueles que, querendo ou não, estiveram sob o domínio das práticas coloniais.

Para tal intento, entende-se que é pertinente realizar uma breve contextualização da teoria pós-colonial (o que se faz na primeira parte). Em seguida, passa-se à análise do referido conto, tendo as implicações teóricas como suporte. A hipótese basilar desse conjunto de ideias é que o texto de João Melo parece trazer, em sua essência, a concepção de que não há mais espaço para posturas radicais nas quais o passado colonial é retomado para se estabelecer antagonismos de qualquer natureza. Coadunado com o pensamento desse escritor angolano, parece estar Homi Bhabha (1998) que tem proeminência nos estudos pós-coloniais na atualidade e se destaca pelo caráter moderado de suas posições ideológicas.

\section{A teoria pós-colonial e a representação político-literária}

As teorias de abordagem do texto literário surgem a partir de contextos históricos que refletem a forma como a sociedade se enxerga perante as mudanças, os roteiros e as experiências vivenciadas. Assim, seria possível indagar: Como surgiu a teoria pós-colonial? Em que espaço? Com quais intenções? Embora não se pretenda oferecer uma resposta cabal e definitiva, é razoável postular que a chamada crítica pós-colonial (fazendo referência aos estudos literários) tem sua gênese no processo de independência das colônias, sobretudo africanas e asiáticas, e se aprofunda quando, mesmo com certa autonomia política, o imaginário coletivo das excolônias ainda se aprisiona ao passado recente de subserviência.

Assim, a ideia de pós-colonialismo não representa uma ruptura categórica com o processo histórico da colonização. No caso, o termo "pós", além do valor semântico temporal, que remete ao período posterior à independência política, indica uma nova fase pautada na ressignificação de uma identidade mestiça que dialoga, inevitavelmente, com o passado e o 
presente. Nessa linha de pensamento, Said expressa o seguinte:

\begin{abstract}
A invocação do passado constituiu uma das estratégias mais comuns nas interpretações do presente. O que inspira tais apelos não é apenas a divergência quanto ao que ocorreu no passado e o que teria sido esse passado, mas também a incerteza se o passado é de fato passado, morto e enterrado, ou se persiste, mesmo que talvez sob outras formas. Esse problema alimenta discussões de toda espécie - acerca de influências, responsabilidades e julgamentos, sobre realidades presentes e prioridades futuras (2007, p.31-32).
\end{abstract}

O comentário do teórico acima citado, expoente na construção da teoria pós-colonial, deixa patente que existe a premência de uma reinterpretação das relações que foram estabelecidas no passado entre povos de culturas distintas. Desse modo, poder-se-á reescrever os fatos de maneira mais imparcial onde não prevaleça a voz do vencedor.

Em relação aos agentes formuladores dessa corrente teórica, é sabido que: grande parte dos estudiosos que ajudaram a desenvolver essa teoria, que busca outorgar uma nova representação cultural aos sujeitos colonizados enquanto detentores de discursos próprios e, portanto, capazes de representar a si mesmos, estão em um espaço de diálogo entre o que se chama de ocidente (dominantes) e oriente (subalternos). Assim, em sua maioria, professores de renomadas universidades da Europa Ocidental e dos Estados Unidos, esses teóricos de origem "periférica" são responsáveis pela disseminação de um novo modo de pensar as relações culturais e de representação simbólica entre o que, em tempos de outrora, se denominava metrópole e colônia.

Sendo assim, quanto ao lugar de manifestação da teoria pós-colonial, pode-se dizer que não é fixo, pois os indivíduos que se "engajam" nessa proposta teórica subversiva, no sentido positivo do termo, embora oriundos de espaços colonizados, vivenciam a experiência de uma vida ocidental. Para Bonnici (1998) a crítica pós-colonial surge como uma alternativa teórica que visa compreender as influências imperialistas em aspectos culturais de povos que foram marginalizados e oprimidos em decorrência do processo colonial.

Além disso, não é hiperbólico considerar que essa incipiente forma de abordagem teórica, que envolve a arte literária, se propõe a uma nova configuração epistemológica e cultural dos povos colonizados para que os mesmos possam se equiparar aos países historicamente imperialistas. Reitera-se, portanto, que a possibilidade de as ex-colônias poderem expressar por conta própria a sua identidade, está, portanto, no cerne da questão pós-colonial.

Levando em consideração as complexas relações entre povos de naturezas distintas e a necessidade que o ser humano sempre teve de subjugar o outro, poder-se-ia pensar que a teoria 
pós-colonial, como muitas teorias do campo acadêmico, não se aplicaria numa realidade mais pragmática. Tal pensamento parece equivocado, pois, não obstante se discuta uma necessidade supostamente quimérica de equidade na representação cultural e epistemológica entre sociedades que se colocaram como antagônicas (superior versus inferior), o pensamento póscolonial atua na rota de uma mudança de ideologia que parte do próprio sujeito posto como subalterno.

Como um processo de conscientização de que os indivíduos devem estar livres para se autodeterminarem, a crítica pós-colonial, desse modo, intenta uma reformulação dos sujeitos, dos espaços e das relações de poder em mundo marcado pela globalidade. Nesse sentido, a teoria pós-colonial tem um componente político relevante, pois pressupõe uma reconfiguração de poder simbólico entre espaços que historicamente se mantêm em posição antagônica. Com isso, a desconstrução de uma ideologia que pauta a superioridade do mundo ocidental perpassa por um processo de inserção de novas ideias e do reconhecimento de todo arcabouço sociocultural das comunidades subjugadas na ação colonizatória.

Nessa empreitada que envolve a tentativa de metamorfose de um pensamento centrado na cultura ocidental o qual Said (1990) denominou de orientalismo, a arte e a crítica literária se inserem como instrumentos pragmáticos na reconstituição de consciências que passam a compreender as diferenças socioculturais não mais como binarismos ou hegemonia de uma sociedade sobre a outra.

A propósito, em sua obra Orientalismo: o oriente como invenção do ocidente, considerada o marco da teoria pós-colonial, Said assevera que:

\begin{abstract}
[...] o que temos de respeitar e tentar apreender é a força nua e sólida do discurso orientalista, os seus laços muito íntimos com as instituições sócioeconômicas e políticas capacitantes, e a sua terrível durabilidade. Afinal, qualquer sistema de ideias que possa permanecer inalterado como sabedoria que se pode ensinar (em academias, livros, congressos, universidades e institutos de relações exteriores) desde o período de Ernest Renan no final da década de 1840 até o presente nos Estados Unidos deve ser algo mais formidável que uma mera coleção de mentiras. O orientalismo, portanto, não é uma fantasia avoada da Europa sobre o oriente, mas um corpo criado de teoria e prática em houve, por muitas gerações, um considerável investimento material. $\mathrm{O}$ investimento continuado fez do orientalismo, como sistema de conhecimento sobre o oriente, uma tela aceitável para filtrar o oriente para a consciência ocidental, assim como esse mesmo investimento multiplicou - na verdade, tornou realmente produtivas - as declarações que proliferaram a partir do oriente para a cultura geral. (1990, p. 09)
\end{abstract}

Uma análise atenta das palavras de Said (1990), supracitadas, conduz a uma compreensão 
razoável das propostas subjacentes do pensamento pós-colonial. Em primeiro lugar, fica evidente que as relações estabelecidas entre as antigas metrópoles e colônias não se pautaram apenas pela imposição da força física coadunada com a exploração das riquezas presentes nos territórios ocupados. Houve todo um esforço para se construir um ponto de vista no qual o mundo ocidental estaria num patamar social, econômico, político e cultural mais elevado. Tal ideologia conseguiu, desse modo, se disseminar e persuadir, até mesmo, aqueles que estavam sendo postos como inferiores.

O discurso orientalista, assim, foi calcado à custa de um longo processo de teorização e de divulgação de ideias. Ele se mantém no mundo globalizado sobre as formas modernas de dominação, mas encontra no discurso pós-colonial, um ponto que pode gera mais equilíbrio, caso se cogite a impossibilidade de uma equiparação de forças.

O pensamento pós-colonial, nesse sentido, ao mesmo tempo em que contradiz o pensamento orientalista, não deixa de reconhecer o peso de toda uma tradição que foi desenvolvida ao longo de séculos. Seguindo esse raciocínio, mas com posturas mais radicais, Fanon (2008) destaca a brutalidade dos atos de colonizações que trouxeram impactos na ordem social, política, econômica, cultura e psicológica dos povos colonizados. A proposta de uma "descolonização" pressupõe, assim, o surgimento de indivíduos capazes de superar os sentimentos de inferioridade construídos historicamente. De outro modo, pode-se dizer que esses sujeitos precisam, antes de tudo, libertar a mente para que o passado colonial não surja como um "fantasma" que os condena à eterna situação de subalternidade. Nos termos de Fanon (2008), diz-se que:

\begin{abstract}
Sem dúvida poder-se-ia igualmente mostrar o aparecimento de uma nova nação, a instalação de um novo Estado, suas relações diplomáticas, sua orientação política, econômica. Mas nós preferimos falar precisamente desse tipo de tábula rasa que caracteriza de saída toda descolonização. Sua importância invulgar decorre do fato de que ela constitui, desde o primeiro dia, a reivindicação mínima do colonizado. Para dizer a verdade, a prova do êxito reside num panorama social transformado dia alto a baixo. A extraordinária importância da tal transformação é ser ela querida, reclamada, exigida. A necessidade da transformação existe em estado bruto, impetuoso e coativo, na consciência e na vida dos homens e mulheres colonizados. (p.25-26)
\end{abstract}

Unido a essa ótica, mas com um viés mais ponderado e atento às novas demandas do século XXI, o teórico Homi Bhabha contribui consideravelmente para as discussões que envolvem a crítica pós-colonial. Bhabha (1998) reconhece todo o processo histórico de exploração que alguns países classificados, atualmente, como desenvolvidos ( $1^{\circ}$ mundo) realizaram nas suas 
antigas colônias. Assim, tem-se como reflexo a configuração de um mundo dividido entre ricos e pobres, desenvolvidos e subdesenvolvidos, industrializados e não-industrializados, gerando o que o teórico indiano chama de binarismo.

Em outras palavras, é o duelo entre ocidente e oriente, exposto por Said, no qual o vencedor é sempre aquele que detém a hegemonia do discurso, isto é, o mundo ocidental.Nesse sentido, estabelecendo como foco o aspecto cultural, Bhabha (1998) desenvolve conceitos como hibridismos, terceiro espaço e negociação. Os pressupostos desse teórico parecem ter como cerne a ideia de que é salutar extinguir certas disputas ideológicas (norte $X$ sul, esquerda $X$ direita) na tentativa de uma grande conciliação não no sentido de eliminar as diferenças, mas de estabelecer acordos nos quais os espaços postos a margem tenham direitos e maior relevância nessa nova conjuntura de globalidade. Nesses termos e dissertando acerca dos fundamentos da pós-colonialidade, Bhabha diz que:

\begin{abstract}
A pós-colonialidade, por sua vez, é um salutar lembrete das relações 'neocoloniais' remanescentes no interior da 'nova' ordem mundial e da divisão de trabalho multinacional. Tal perspectiva permite a autenticação de histórias de exploração e o desenvolvimento de estratégias de resistência. Além disso, no entanto, a crítica pós-colonial dá testemunho desses países e comunidades - no norte e no sul, urbanos e rurais constituídos, se me permitem forjar a expressão, 'de outro modo que não a modernidade'. (1998, p.26)
\end{abstract}

Nas palavras de Bhabha (1998) é perceptível que a teoria pós-colonial ganha um teor eminentemente político. Nessa conjuntura, a produção literária de alguns sujeitos, oriundos desses territórios colonizados, se enquadra no que se pode chamar de arte engajada. Assim, é plausível postular que aspectos culturais, políticos e literários são componentes inerentes na formulação do pós-colonialismo.

Nesse contexto, insere-se o papel da literatura como veículo de representação políticocultural de muitas nações que refazem sua identidade e buscam, assim, libertar suas consciências de ideias que possam tolher avanços nas mais diversas áreas da atividade.

Aparentemente inócua, a produção literária pós-colonial surge como uma resposta a um discurso hegemônico que almeja inviabilizar o desenvolvimento dos espaços condicionados à empreitada colonial. Sendo assim, escritores, situados em espaços onde a crise de identidade e a baixa autoestima ainda é significativa, atuam como propagadores de uma nova forma de pensar a relações entre passado e presente.

Não obstante possa existir algum ranço ou recalque de autores ditos pós-coloniais, a atitude 
mais sadia parece ser a de reconhecer a inviabilidade de um discurso radical que divide as nações e/ou propõe uma pureza racial ou cultural. O caso do escritor João Melo, em Angola, é uma demonstração de como é possível romper os entraves psicoculturais e se compreender as novas relações que a globalidade faculta.

\section{Marcas do Pós-colonialismo em "O efeito estufa" de João Melo}

A configuração de uma personalidade híbrida, contraditória, problemáticae recalcada é uma consequência plausível em indivíduos que estiveram condicionados a um processo de colonização. É isso que surge, a priori, no conto "O efeito estufa", presente na obra "Filhos da pátria", do escritor angolano João Melo. Ambientado em Angola, país africano que foi colonizado por portugueses, a narrativa traz um protagonista cujo próprio nome revela os efeitos das influências externas. O nome Charles Dupret é, explicitamente, a junção de um termo inglês com um francês. Mesmo como traço de uma constituição híbrida, até, na sua identificação civil, o referido personagem tenta expressar, paradoxalmente, uma visão calcada em um nacionalismo-racial repleto de radicalismos:

\footnotetext{
Charles Dupret. Apesar de ter esse nome, claramente anglo-afrancesado, ele era o mais acérrimo defensor da autenticidade angolana. Angola é um país de preto! Esta frase contundente e absoluta estava presente em todos os discursos que fazia, mesmo quando falasse apenas do estado do tempo. Estava totalmente à vontade para brandir a referida sentença contra tudo e contra todos, pois não era um desses pretos suspeitos, meio acastanhados, cujo cabelo, quando cortado bem rente, se torna liso e dócil ao tacto e que, um tanto equivocadamente, se chamam a si próprios "fulos"... (2008, p.59)
}

Vê-se que o personagem principal começa sendo retratado como um sujeito engajado numa luta ideológica, política e cultural em defesa de uma pureza racial e da autenticidade de sua pátria: Angola. Com esse início meio caricatural, João Melo parece revelar o caráter mimético da sua literatura, pois o protagonista do conto representa o espectro de um processo de colonização seguido por uma complexa independência política que deixaram marcas no psicológico e na cultura em indivíduos os quais se tornaram desajustados.

Assim, ao repetir o mantra "Angola é um país de pretos!", Charles Dupret reproduz o recalque com quem deseja negar um passado de subalternidade e de sérias alterações nas estruturas econômicas, políticas e culturais de uma terra cuja identidade nacional foi 
reconfigurada pela ação dos colonizadores.

A vã tentativa da conservação de costumes e modos de ser dos sujeitos angolanos, leva Dupret a se distinguir e criticar aqueles que, de alguma forma, deixaram se "contaminar" pelos modismos do colonizador europeu. Os cabelos lisos, o uso de óculos e um comportamento que se assemelha ao mundo ocidental são rechaçados pelo protagonista. O que para os sujeitos híbridos de Angola, a mistura de culturas representa o desaparecimento de fronteiras entre povo colonizador e povo colonizado, para Dupret é uma grave ofensa aos preceitos da nação angolana. Nas palavras do narrador, o que na verdade representa o pensamento do personagem, ocorre o seguinte:

\begin{abstract}
[...] gostam de chamar 'fronteiras perdidas', o que é uma notória sacanice (palavra que, caso sejam sensíveis à escatologia, podem substituir, por exemplo, por perfídia). Pelo contrário: ele era um preto genuíno, sem qualquer pigmento a mais ou a menos! Um verdadeiro autóctone angolano! Podia, pois, proclamar à vontade que Angola é um país de pretos! (2008, p.59)
\end{abstract}

A ideia expressa no termo "fronteiras perdidas" revela bem o sentimento de alguns angolanos, que assimilaram o pensamento de que o processo colonial alterou tão drasticamente as estruturas socioculturais de Angola que seria inviável o retorno a traços de homogeneidade cultural do passado pré-colonial. Assim, o DNA do colonizador estava definitivamente impregnado na genética do nativo de Angola. Não havia, portanto, como retroceder a esse processo de mestiçagem.

Dessa forma, o que o escritor João Melo parece representar na figura do protagonista é a existência de uma visão mitológica por parte de indivíduos que se julgam pertencente a uma nação cuja autenticidade fosse preservada, não obstante aos processos históricos a que esteve submetida. Stuart Hall (2003), em sua obra "Da diáspora: Identidade e mediações culturais", descreve algumas nuances dessa inadaptação a uma realidade de hibridismo cultural:

\footnotetext{
Trata-se, é claro, de uma concepção fechada de "tribo", diáspora e pátria. Possuir uma identidade cultural nesse sentido e estar primordialmente em contato com um núcleo imutável e atemporal, ligando ao passado o futuro e o presente numa linha ininterrupta. Esse cordão umbilical é o que chamado de "tradição", cujo teste e o de sua fidelidade às origens, sua presença consciente diante de si mesma, sua "autenticidade. É, claro, um mito - com todo o potencial real dos nossos mitos dominantes de moldar nossos imaginários, influenciar nossas ações, conferir significado às nossas vidas e dar sentido à nossa história (p.29).
}

Hall (2003) ao enfatizar que para alguns sujeitos ex-colonizados existe a necessidade de 
manterem vivas as tradições que identificam suas origens, justifica a tensão psicológica e a política. A primeira refere-se a ideias revolucionárias que se formulam na mente dos indivíduos. A segunda ocorre quando se pretende pôr em prática ações que impeçam a influência da cultura externa ao mesmo tempo em que se busca resgatar costumes passados os quais foram suplantados pela cultura dos colonizadores.

O embate que se trava entre passado e presente, nesse caso, tem com finalidade a construção de um futuro no qual seja possível a representação de sociedade detentora de elementos culturais próprios. Com esse ideal, o personagem Charles Dupret se constitui uma metonímia com a qual João Melo satiriza os possíveis engajamentos de natureza ufanista e racial de sujeitos que não ainda não compreenderam a inexorabilidade do processo colonial.

Sendo assim, para expressar seu pensamento, o escritor angolano se utiliza de um narrador em primeira pessoa que tem a peculiaridade de dialogar com o leitor. Marcando posição desde o início, esse narrador relata os fatos com quem tivesse testemunhado de perto o enredo que envolve o protagonista. De forma inusitada, o narrador homodiegético antecipa o fim da história e revela sua opinião acerca de Dupret:

\begin{abstract}
Reconheço que, seja como for, esta técnica de antecipar o fim das estórias, além de não ser nada de novo, não anula o facto de que o desenlace, ainda que (ou sobretudo) simbólico, tem os seus quês e porquês, razão por que, e embora pessoalmente não tenha grandes motivos para gostar de Charles Dupret, serei obrigado (espero e confesso: com secreto gozo...) a transmitirIhes os resultados da minha investigação ficcional, se é que isso existe... Os leitores dirão, no final, se fiz dele um retrato sereno e objetivo ou uma mera e grotesca caricatura, motivada pelos meus eventuais e humanos preconceitos. É que, como se sabe, a verdadeira distância entre autor e narrador depende somente do grau e do tipo de dissimulação (MELO, 2008, p. 60-61)
\end{abstract}

Como se constata, o narrador conduz a narrativa de um modo bastante diverso e com um sarcasmo capaz de surpreender o leitor. A expor o seu não apreço pelo protagonista e defender a ideia que existe uma linha tênue entre narrador e autor, o narrador de João Melo instiga, ainda mais, uma discussão que parte de uma ficção para realidade ou vice-versa. Com esse mimetismo, Melo se posiciona como um cidadão angolano que enxerga as nuanças e os reflexos da colonização portuguesa em Angola sem o viés radical dos que tentam negar, levianamente, a existência de uma nova sociedade heterogênea, multicultural e globalizada.

Na condição de representante desses sujeitos desajustados e contraditórios diante de uma situação de mistura cultural e mesmo com certa supremacia de alguns legados coloniais, Dupret 
dizia ser o único estilista preto em Angola. Tal profissão servia para confirmar a ideologia de teor nacionalista e racial do personagem. Ele só trabalhava com modelos pretos os quais só utilizavam roupas pretas. A abertura dos desfiles, segundo o narrador, era algo esdrúxulo, o que merece destaque: "Senhoras e senhores, vão passar a seguir as pretas e os pretos autênticos de Charles Dupret, os únicos que são imunes ao efeito estufa" (MELO, 2008, p.62).

Merece destaque, nessa parte do conto, o fato de ser mencionada a cor preta (nas roupas e na pele das modelos) como uma imunização ao efeito estufa (título do conto). Tal afirmativa remete a ideia de pureza nacional e racial, ou seja, com Dupret, Angola não cedia aos modismos do mundo globalizado. É óbvio que toda essa ideia é exposta para ser descontruída no desfecho da narrativa.

Ademais, seguindo em oposição às atitudes do protagonista, o narrador ressalta que o estilista era festejado por muitos compatriotas e por alguns jornalistas que acompanhavam os desfiles. A contradição surge quando um jornalista protesta ao dizer que apenas os brancos tinham condições de comprar aquelas roupas, pois eram muito caras. A desculpa de Dupret pautava-se na necessidade de explorar os brancos colonizadores como uma espécie de reparação pelo que fizeram no passado.

Outro episódio, ressaltado pelo narrador, é uma situação de almoço em família na qual o personagem central (taxado como ditador) decreta que a partir daquele momento ninguém mais da família comeria bacalhau, pois o peixe representaria a herança do colonialismo português em Angola:

\footnotetext{
[...] decretou definitivamente, como se disso dependesse não apenas a integridade, mas o próprio futuro daquela pequena célula da pátria que a família, pelo menos no seu entendimento, ele que era considerado como o maior defensor público da autenticidade angolana. A partir de hoje, o bacalhau deixa de fazer parte da dieta alimentar desta casa!, para desespero da mulher e dos filhos, que ficaram sem saber o que fazer com os garfos que tinham à frente da boca. (MELO, 2008, p.65-67)
}

Em contraposição aos excessos de Dupret, comparável ao personagem Policarpo Quaresma de Lima Barreto no tocante à necessidade de rejeitar qualquer elemento de outros países como forma de enaltecer a sua própria pátria, o narrador põe em cena a filha do estilista (estudante em Londres e que estava de férias em Luanda) para desmontar o argumento do pai ao afirmar que o bacalhau, na verdade, tinha origem na Noruega e não em Portugal. Mesmo assim, o ditador da família não se rende e argumenta que seria pior ainda, pois aquele peixe seria covarde por deixar-se capturar pelos portugueses como fizeram os angolanos colonizados. 
Nesse ponto da narrativa, parece ficar evidenciada a representação de um sujeito híbrido e recalcado. O hibridismo cultural, conceito desenvolvido por Bhabha, refere-se ao fato da inevitável incorporação de novos elementos culturais resultantes das interações sociais do processo de colonização. Ou seja, o indivíduo pós-colonial não tem como negar que o passado colonial o transformou em um sujeito marcado por uma densa heterogeneidade cultural.

Desse modo, o anacronismo do personagem, satirizado pelo narrador/autor, tem em seu bojo, também, o que Freud (1996) chamou de recalque. Segundo o psiquiatra austríaco, o recalque ocorre quando o indivíduo tenta, a todo custo, suplantar seu passado, ou seja, as bases que podem revelar sua real identidade. Assim, esse sujeito põe no inconsciente as lembranças traumatizantes e enaltece uma outra realidade inventada como forma de anestesiar a dor e oferecer sentido para a vida.

Tal destempero psicológico do personagem supracitado passa, desse modo, por um processo de desmascaramento devido aos paradoxos existentes entre seus discursos, ações e os fatos concretos. Nesse ínterim da narrativa ressurge a figura do jornalista, já citado, para revelar que os roupas "idealizadas" por Charles Dupret, eram na verdade, plágios de vestimentas árabes. Dupret era posto, assim, como um farsante, ou nas palavras do narrador "Charles Dupret limitava-se a copiar servilmente os padrões de beleza europeia" (MELO, 2008, p. 68).

Sendo assim, o desenlace da narrativa apresenta a passagem do aspecto cômico, representado na voz do narrador, a situação trágica acometida àqueles que conseguem lidar com as próprias nuanças socioculturais e históricas inerentes à complexa e inacabada constituição da identidade humana. Com isso, após expulsar a família de casa por esta não obedecer ás suas imposições esdrúxulas, Charles Dupret enlouquece incorporando, ironicamente, alguns traços da cultura europeia que já tinham sido assimilados pelos colonizados que ele, antes, insistia em negar:

\begin{abstract}
A verdade é que, a partir dali, os acontecimentos precipitaram-se irremediavelmente, até ao fatídico dia já anunciado no início desta estória, quando - era o que faltava dizer - o estilista foi visto em plena Mutamba, em cima de uma espécie de passarela colocada sobre uma fila de cinco contentores de lixo, disfarçado de Michael Jackson, com um pedaço de gadusmorrbua em cada mão, ensaiando uma coreografia absolutamente original. (MELO, 2008, p. 71)
\end{abstract}

Dessa forma, o desfecho trágico-cômico do personagem parece trazer uma reflexão no tocante as novas relações, sobretudo político-culturais, a serem estabelecidas, na contemporaneidade, entre povos e nações que, porventura, ainda guardem o ranço de um 
passado no qual se puseram em antagonismo o opressor e o oprimido. Embora seja evidente que as relações internacionais não sejam equânimes pela própria disparidade de poder político, ideológico e econômico, não será um discurso de revanchismo que irá reparar algum desatino de outrora.

A proposta de Bhabha (1998) parte do princípio da negociação. Tal postura parece ser mais sensata, pois seria quimérico, para não dizer insano, querer reverter, tão drasticamente, um processo histórico que formulou e continua configurando a humanidade há séculos. A dica deixada pelo narrador/autor é que o ser humano, independente das diferenças de nacionalidades, de aspectos raciais ou culturais, faz parte de um mesmo planeta cujas fronteiras e os muros precisam ser, mesmo que simbolicamente, rompidas, já que "ninguém consegue escapar do efeito estufa". Ou seja, o irreversível processo de globalização tolhe qualquer tentativa de isolamento ou homogeneidade cultural. Assim, não obstante haja uma certa supremacia de espaços que foram hegemônicos no passado colonial, a realidade do mundo é pautada por relações que o torna híbrido, multicultural e sem fronteiras predeterminadas.

\section{Considerações finais}

A constituição das sociedades no mundo, ao longo de todo processo histórico, perpassa por uma série de fatores tais como: poder econômico/militar, ideologia político-religiosa e defesa de aspectos culturais. Nessa conjuntura, as consequências do que se denomina de processo colonial, ficam evidenciadas na própria configuração dos continentes e países da contemporaneidade. As enormes disparidades de desenvolvimento socioeconômico e os desníveis de condições de representação cultural, identitária e política são realidades que, por vezes, põem em situação de antagonismo as nações que foram subjugadas na empreitada colonial em relação aos países colonizadores.

A teoria pós-colonial, nessa lógica, outorga uma possibilidade de uma reflexão acerca de um passado que se projeta em um presente de desigualdades regionais. Ademais, de forma mais pragmática, traz, em seu âmago, o desejo e a proposta de mudanças no sentido de conferir maior reconhecimento e autonomia a espaços historicamente explorados e marginalizados. Como uma corrente teórica heterogênea, o pensamento pós-colonial dialoga com diversas áreas do conhecimento. Da Sociologia à Literatura, a crítica pós-colonial apresenta, séculos de relações interculturais impositivas e injustas nas quais diversos povos tiveram um enorme detrimento de sua autonomia política e cultural, o entendimento mais razoável de todo esse processo histórico, que ainda continua, é de que há a necessidade de amenizar as disparidades 
de poder que constitui antíteses: ocidente/oriente, desenvolvido/subdesenvolvido.

Como ponto de interação com os pressupostos da teoria pós-colonial, a arte literária é eficaz na representação de uma realidade na qual sujeitos pós-coloniais não digeriram de forma satisfatória os resquícios dos tempos de embate entre metrópole e colônia. Nesse sentido, o conto analisado, "O efeito estufa" do escritor angolano João Melo, apresenta traços dessa realidade na qual os indivíduos são sintomáticos quanto as suas memórias dos tempos coloniais.

Em Angola, como em toda África com as suas mais diversas nuances, a ideia de descolonização, após um longo período de dominação, não poderia de deixar de ser problemática. Assim, os desequilíbrios psicológicos e os radicalismos ideológicos são recorrentes nesses territórios cujas identidades e fronteiras foram reconfiguradas.

Sendo assim, a figura do protagonista Charles Dupret, caricatura exposta por João Melo, não deixa de ser a representação de uma coletividade, historicamente, mal resolvida com os seus próprios conflitos psicoculturais oriundos da colonização. Com isso, os recalques e hibridismos simultâneos, na conjuntura exposta, fazem parte de uma realidade marcada pelas complexas interações humanas nas quais não se podem estabelecer regras e/ou resultados cabais. Logo, as propostas de ações mais assertivas no sentido de alterar as estruturas construídas historicamente são cada vez mais ilusórias quando se defende posições separatistas ou de revanchismo. Nesse sentido, o fim tragicômico do personagem Charles Dupret, mesmo com o caráter metafórico e paródico possibilitado pela arte literária, simboliza uma situação plausível de sujeitos que não se adaptam a contextos nos quais as culturas e as identidades estão em constante alteração de rota.

\section{Referências}

BHABHA, H. K. O local da cultura. Belo Horizonte: UFMG, 1998.

BONNICI, T. Introdução ao estudo das literaturas pós-coloniais. Mimesis, Bauru, v. 19, n. 1, p. 07-23, 1998.

FANON, F. Peles negras, máscaras brancas. Salvador: Editora EDUFBA, 2008.

Os condenados da terra. Minas Gerais: Editora UFJF, 2008.

FREUD, S. (1915) Recalque. In: Obras psicológicas completas: Edição Standard Brasileira. Vol. XIX. Rio de Janeiro: Imago, 1996.

HALL, S. Da diáspora. Identidades e mediações culturais. Trad.: Adelaine La Guardia Resende et al. Belo Horizonte, 2003.

ALMEIDA, J.; RIBEIRO, A. M.; GOMES, H. T. Crítica pós-colonial: panorama de leituras contemporâneas. 1.ed. 7 Letras: Rio de Janeiro, 2013. 
MELO, J. O efeito estufa. In: Filhos da Pátria. Rio de Janeiro: Record, 2008

SAID, E. W. Orientalismo: o Oriente como invenção do Ocidente. Nova edição. Trad.: Tomás Rosa Bueno. São Paulo: Companhia das Letras, 1990.

Cultura e imperialismo. Trad.: Denise Bottmann. São Paulo: Companhia das Letras, 2007.

Recebido em: 14/01/2019.

Aceito em 17/05/2019. 